\title{
Onion layers as a natural concept and inspiration to improve building performance
}

\author{
Z. Shawaf \& H. Taleb \\ Sustainable Design of the Built Environment, \\ British University in Dubai, UAE
}

\begin{abstract}
Nature is a vast inspirational source which we can learn from. Human beings are guided by nature, because nature is ancient with its 3.8 billion years of existence and knowledge of what works and lasts here on Earth.

Biomimicry is an innovative way to observe, inspire and value nature and henceforth to learn from it and find and derive solutions from natural models to solve human problems. An environmental standard is used to evaluate the status of our innovations. At the present time, mimicking these designs and natural strategies can change our concept of extracting from nature and instead focus on what nature can teach us and how we learn and emulate the shapes, processes and systems in architecture from natural ways. A more detailed understanding of this subject is prepared to solve complicated problems which Mother Nature manages to solve. This project aims to explore, study and develop sustainable solutions by biomimicking elements from the offerings of Mother Nature and following strategies that mirror those natural elements in order to resolve a particular problem within an architectural case study that exists in identical climatic conditions. Moreover, this work focuses on innovative solutions for thermal, acoustic and lighting comfort inspired by nature. Biomimicry is a problem-solving methodology, looking to the natural world for models for new technologies. In multiple disciplines, biomimicry is a successful concept.

Keywords: biomimicry, sustainable, onion layers, nature, environment, educational building, thermal, lighting comfort, acoustic.
\end{abstract}




\section{Introduction}

Biomimicry is an innovative way to observe, inspire and value nature, to learn from it and find and derive solutions from natural models to solve human problems. An environmental standard is used to evaluate the validity of our innovations. At the present time, mimicking natural strategies could change our concept of extracting from nature and instead focus on what nature can teach us and how we learn and emulate the shapes, processes and systems in architecture from a natural perspective. Biomimicry is a problem solving methodology, looking to the natural world for models for new technologies. In multiple disciplines, biomimicry is a successful concept. The nature of this case study was an educational facility which required attention to the comfort of students and staff from the aspect of thermal comfort and stability of temperature especially in such a hot environment, the intention being to enhance overall human productivity. The second objective of this study is to inspire an approach to enhance the building envelope from the richness and variety of natural concepts and creativity. This is with the aim of taking the building envelope and properties such as function, dimension, position and orientation into the area of biomimicking these concepts and incorporating them into the envelope giving it optimal performance with respect to thermal, visual and acoustic comfort.

Inspired by onions and tulip bulbs, strategies were applied to the case study to solve problems such as reducing heat absorption and providing thermal and acoustic insulation. Last but not least it has been concluded that applying the natural concept of the onions papery outer shell and layers is a way of protecting the inner core. By biomimicking this structure to existing building's envelope and the analysis done by ECOTECT program, results found that it would moderately decrease the load on HVAC and total electricity consumption as well as improve the quality of the environment for working staff, students and other users of the building.

The aim is to explore study and develop sustainable solutions by biomimicking elements from the offerings of Mother Nature and follow strategies that mirror those of the natural elements in order to resolve a particular problem within an architectural case study that exists in identical climatic conditions. This is in addition to focusing on innovative solutions for thermal, acoustic and lighting comfort inspired by nature [1].

The objective of this paper is to inspire an approach to enhance the building envelope from the richness and variety of natural concepts and creations. The intention is to take the building envelope with its properties such as function, dimensions, position and orientation, then biomimicking these concepts and incorporating them into the envelope giving it optimal performance with respect to thermal, visual and acoustic comfort. 


\section{Literature review}

\subsection{Natural concepts}

The onion is a pungent vegetable scientifically named and introduced as Allium Cepa, the genus and species is the Cepa group and it is classified as a vegetable. Onions grew in Ancient Egypt and ultimately arrived in Rome. They can grow in any type of soil or what is known as loamy soil with a natural ph. They are cold season crops that are not delicate and are easy to grow because of their hardiness. They have moth-repelling properties and repel ants, aphids, flea beetles, mosquitoes and carrot flies [2]. Research has shown that onions have anti-asthmatic properties associated with their organosulphur components which prevent the inflammatory reactions in asthma [3].

Some flowering plants develop modified stems under the ground known as bulbs. Onions and tulips are examples of these plants and their bulbs store food and water for the plant through cold and dry seasons. These bulbs confer a globular shape, consisting of concentric strata, or layers, of fleshy leaves that surround the short stems. Lateral bulblets can grow at the bottom of the main bulb. Onions are a type of bulbs that have thin paper-like outer coverings to preserve the fleshiness of the leaves (fig. 1). Alliums are plants that grow in sunny, open, dry sites and in fairly arid climates. They are counted as weakly competitive, so are not usually found in dense vegetation, but instead many species are found on dry mountain slopes, steppes, open rocky or stony sites and summer-dry scrubby vegetation.

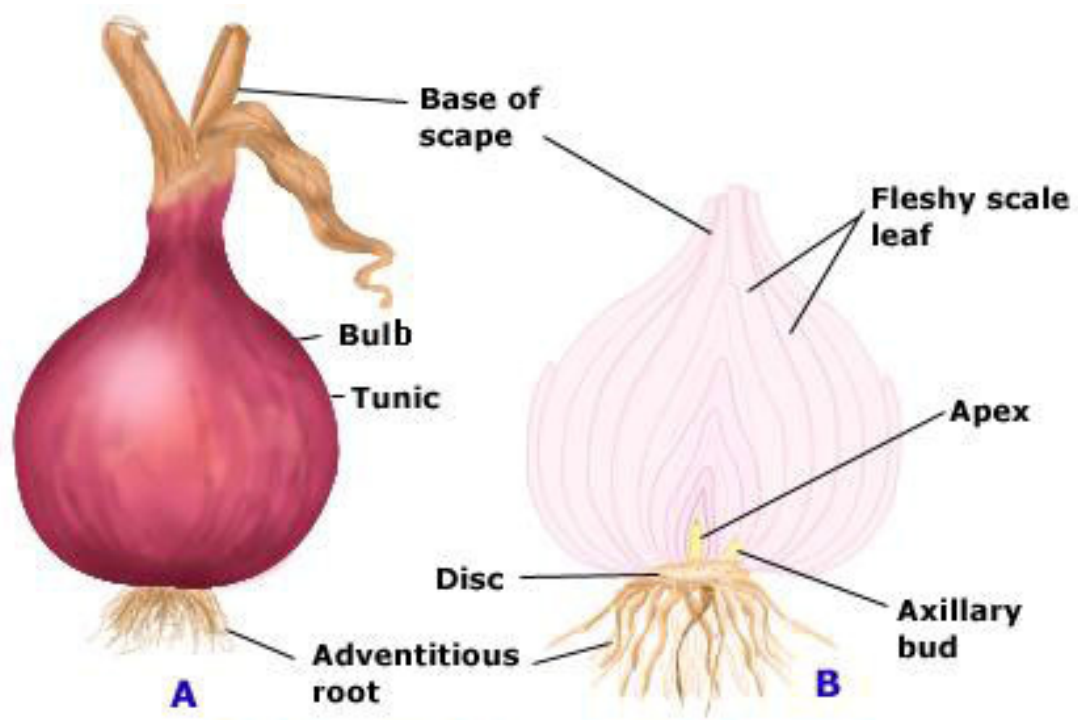

Figure 1: Cross section of the bulb. 


\subsection{Case study}

The nature of this case study is an educational facility located in Ajman in the UAE. It requires attention in terms of the comfort of students and staff from the aspect of thermal comfort and stability of temperature especially in such a hot environment, in order to enhance overall human productivity.

\subsection{Analysing the Ajman/UAE climate}

The UAE weather in general - including Ajman - is hot and humid during the summer months of July and August. The temperature is between $35 \mathrm{c}$ and $44 \mathrm{c}$ and decreases in the spring/winter season to be more moderate and reaches $10 \mathrm{c}$ during December and January.

\subsection{Applied strategy}

The outer papery layer of the onion protects the inner part and keeps it fleshy, similar to trying to protect the core of a building by adding different strategies to improve building efficiency.

\subsubsection{Strategy 1: acoustic insulation and thermal insulation}

2.4.1.1 Noise Noise pollution is redundant and it critically harms people's wellbeing in their daily activities at work, school, and home and during relaxation time as well. It affects social behaviours and stimulates annoyance, moreover it affects the cardiovascular system as well as the psycho-physiological system when it perturbs sleeping.

A major environmental concern and annoyance nowadays is noise pollution, especially in urban areas which can cause stress and discomfort over a long constant period of time. Technologies have been improved to reduce noise from all sources, whether it comes from the outside or inside of any building such as offices, residences, medical or educational buildings [4]. Pursuing this further, [5] it has been pointed out that the most important factor which has to be taken into consideration in educational buildings is noise pollution, which has a direct effect on the efficiency of learning in those facilities. The impact appears to be on learner ability to attain, engage and attend and their wellbeing. Further findings [5] showed that noisy surroundings hinder language and reading development by annoying and distracting the learners and further affecting the liability of their performance in memory tasks. There are two sources of noise that educational facilities are exposed to: external and internal. External noise comes from the surrounding environment such as, construction sites, noisy roads, airport noise or electrical generators, railways, motorways and industrial areas. Internal noises are those arising from within the facility; including noise intrusion leaking from other classrooms or laboratories and background noises often generated from ventilation and cooling systems and from equipment like computers, projectors, printers and copy machines. Finally, students engaging in learning activities are also a source of noise. 
The building skin envelope is essential in the investigation of a building to control noise and heat transmission from the building's exterior envelope to the interior. It is of huge significance to the health of the user and energy conservation and protection to ensure conditions of thermal, visual and acoustic comfort in places with the least energy consumption. Controlling physical environmental factors such as heat, light and sound is one of the most vital functions of the building envelope to identify a situation of comfort for users with the minimum amount of energy consumption [6].

The type of glass which the designer can choose is the parameter to which the level of noise can be reduced, especially when the building is near a main road and other sources of noise. Furthermore when used in skylights or roof glazing windows should provide insulation from the sound of the rain; this is what can be called acoustic glass.

In order to influence the interior climate of a building, interior designers used to select double- or triple-glazed window frames. It has been proven that efficient windows and skylights can reduce a quarter of the building's energy consumption. By using a low-E coating on double-layer windows, this has an effect on the capacities of absorption or reflection of solar radiation (fig. 2). This may be costly but in the long term it can lessen the percentage of energy loss, hence manipulating the economy of countries by saving millions of dollars per day [7].

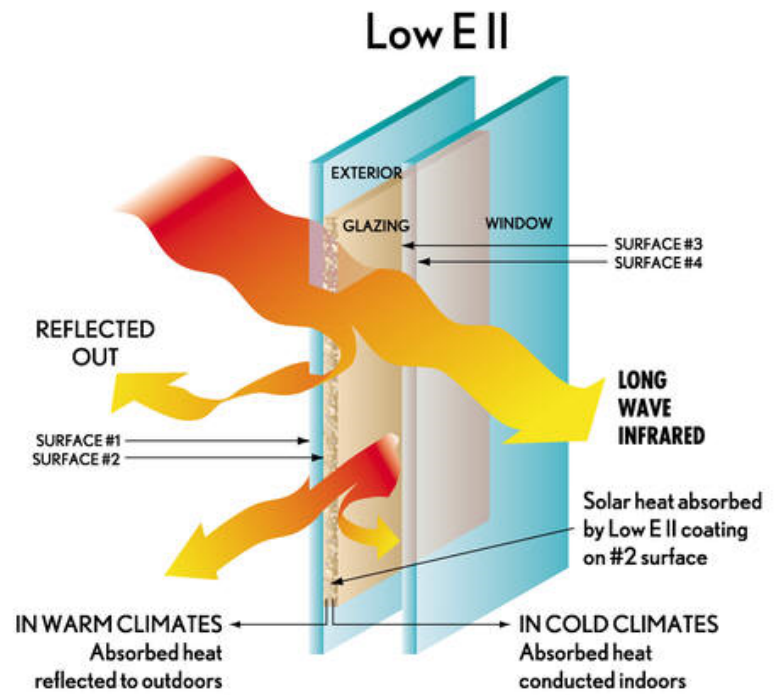

Figure 2: Low-e double glazing.

Double-glazing window installations can solve noise and thermal problems. The (DGU) consists of several components to be fitted into the window, joined together with one or more acoustic interlayers. Two low-emissivity glass panels with a void in between could be filled with gas or air and other components to 
insulate both heat and sound. The interlayer acts as a noise-diminishing core. It works by fading sound as it passes through the glass. Additionally, as the thickness of the glass sheets increases, so do the insulating properties of the overall DGU [8].

Low emissivity glass as known low-e glass, is a type of glass used on double or triple-glazing windows. This thermal insulation coat should be applied on the 2nd or 3rd face of glazing. It is a transparent metallic material that can cut down heating energy. The double-deed layer - also known as passive solar heat gain reflects heat into the room and allows light and heat from the sun to pass through [8].

For the best thermal insulation of glass and windows, new dispensations are being introduced. Thermal insulation glass has become common, so different new properties have been added to improve the double glazing strategy. Some of these advances include 'self-cleaning' glass which can be combined with solar control glass for an easy to preserve solution which avoids excess heat in the summer. This type is preferable for use in conservatories and high-rise buildings which do not have access to the outdoors.

2.4.1.2 Combining acoustic glass with other solutions In a double-glazed window, now with progressing developments, options are available to combine laminated acoustic glass with a variety of low-E, solar control, decorative and self-cleaning glasses (see Which Glass Combinations?).

\subsubsection{Exterior shading device}

Solar energy is the most important factor affecting architecture in a hot climate region. It impinges on the inside and outside of the buildings. By concentrating on the role of the building skin envelope we can control the outcome of solar energy on the indoor environment. The building skin plays a role as a filter between exterior conditions and those within the building [8].

There are many solutions at hand for treating openings in order to eliminate or reduce solar radiation and heat gain. Proper orientation, manipulating size and locations are some options, as well as building envelope-related arrangements like wall protection, balconies, a roof overhang and colonnades.

There are numbers of pros related to exterior shading devices that contribute to sustainable buildings. First, they reduce the amount of solar gain through windows. It is, however, sometimes possible to attain a high performance which is equal to un-shaded high performance glazing. Second is that peak electricity demand is reduced when adding the shading. The final positive is the ability to eliminate glare in interior spaces without using blinds [9]. The most effective are shading devices; functioning by excluding or reducing solar radiation and moreover reducing glare and offering protection from rain. The level of solar protection factor is directly affected by the materials composing the shading devices, these devices are essential in buildings.

Architects and designers have found that by using shading systems on buildings facades, a comfortable productive and dynamic environment for all building occupants can be created. If that system of sun control is properly 
designed, then heat gain can be reduced by around $85 \%$ and hence energy consumption is also reduced by removing the need for the HVAC system thanks to fixed and dynamic solar shading.

Good examples of efficient solar shading systems which can minimise building energy are Solarmotion ${ }^{\circledR}$ and Airfoil. They work by tracking the sun and effectively controlling the light and heat entering the interior space. They work at all times of the day across the year, so that the users of the building can always enjoy natural daylight. By implementing this system, architects and designers can gain important credits from LEED and BREEAM and this will help them in gaining acquiescence with the Building Regulations Approved Document L2 (2002), at the same time also leading to client demands for more energy-efficient buildings.

Made from different materials, such as timber, laminated glass, clear acrylic aluminium, or to be made to a custom design according to the designer's requirements, the blades are operated by hidden motors and are available with three options.

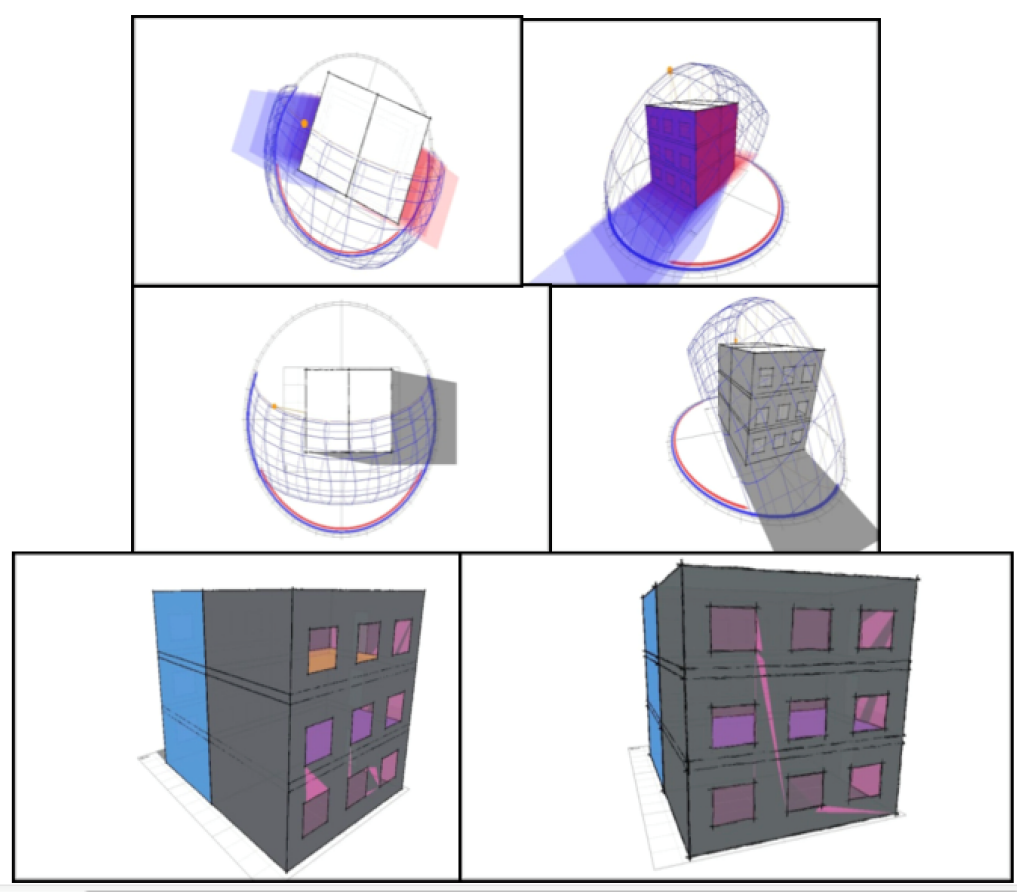

Figure 3: Captures from ECOTECT. 

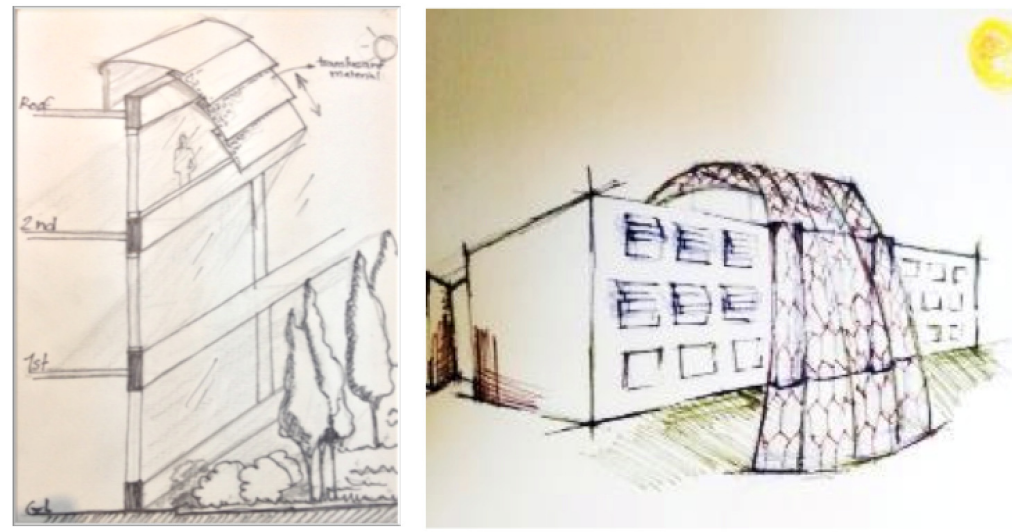

Figure 4: Sketches (source: authors).

\subsubsection{Thermal insulation}

One of the most effective and valuable energy-conservation measures in buildings is thermal insulation. Regardless of the prevalent use of insulation materials in recent years, it is rare to know the optimum thickness under active thermal conditions. Insulated concrete blocks are one of the most commonly used units in the construction of building walls in Saudi Arabia and the UAE. Normally, the insulation sheet thickness is fixed at a value in the range 2.5$7.5 \mathrm{~cm}$, whatever the state of the climate is, with no change in the type and cost of insulation materials and other economic parameters (fig. 5).

The key device in designing and constructing an energy-efficient building is the insulation material. This can be verified by increasing the insulation layers used in buildings. The insulation materials are known for two similar performances, the first being an inorganic fibrous material, while the other is an organic foamy material. Over the last decade thermal material properties have

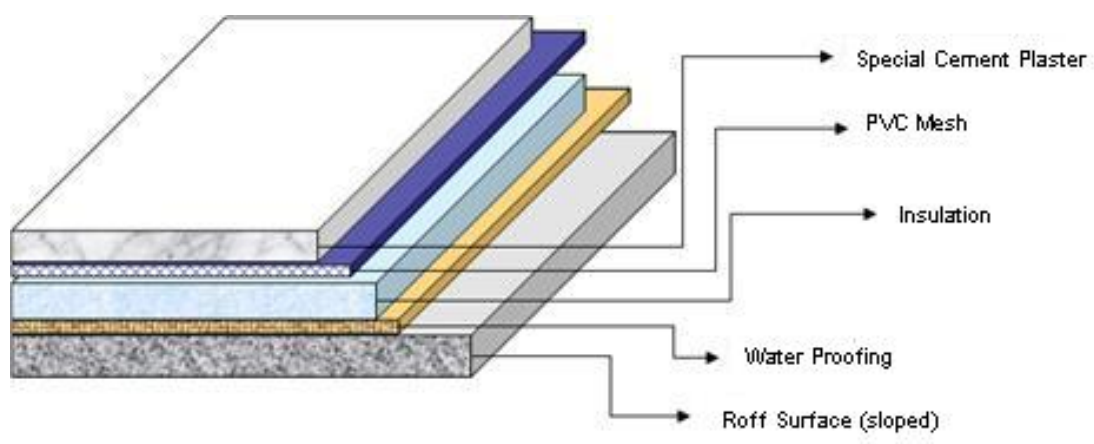

Figure 5: Roof thermal insulation. 
not improved extensively, but they have shown a huge upgrade in areas like fire reaction and the moisture and mechanical properties have also developed to meet the standards of environmental and public health.

In addition, thermal insulation is always required in a move towards the development of a building's energy efficiency. Moreover, in various countries construction practices have a tendency to implement insulation measures incompletely and improperly or with insufficient material, or only as foreseen by regulations. Consequently, thermal losses are in practice greater than those predicted during the design stage. Fig. 6 illustrates the reduction in the cooling load.
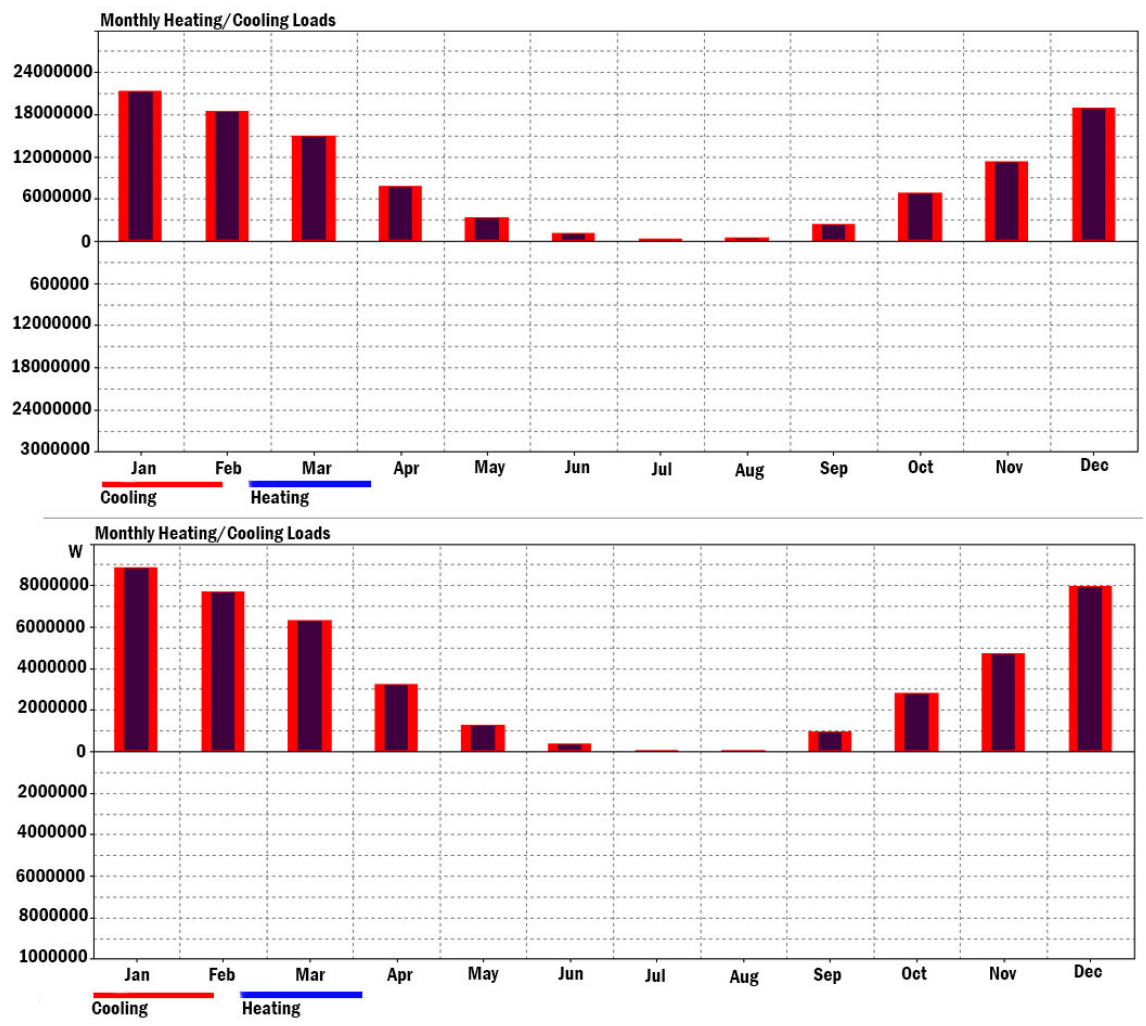

Figure 6: The reduction in the cooling load.

\section{Conclusion}

Applying the natural concept of the onion's papery outer shell and its layers showed a way of protecting the inner core of a building. Biomimicking this structure to the building's envelope and after analysis by ECOTECT program, results found that it would moderately decrease the load on HVAC and the total 
electricity consumption as well as improve the quality of the environment for working staff, students and other users of the building.

\section{Acknowledgement}

The authors would like to thank "MUSTADAMA Ltd. Sustainable Solutions" in Masdar City-Abu Dhabi for sponsoring this paper to be presented in the "Sustainable Development and Planning Conference" held in Istanbul in May 2015.

\section{References}

[1] van der Brugge, A.J.N. (2010). Biomimicry for Light Regulation in Building Envelopes. Master's thesis. Delft University of Technology.

[2] Srikanth, R. (2014). Natural repellents: A brief overview of plants that repel pests, bugs and insects. HubPages [online]. [Accessed 27 February 2014]. Available at: http://srirad0675.hubpages.com/hub/Natural-repellents-Abrief-overview-of-plants-that-repel-pests-bugs-and-insects

[3] National Onion Association. (2011). Health Properties of Onions [online]. [Accessed 20 February 2014]. Available at: http://onions-usa.org/ media/view/14/Health-Properties-of-Onions

[4] Double Glazing Info. (2008). Types of Glass [online]. [Accessed 28 February 2014]. Available at: http://www.double-glazing-info.com/ Choosing-your-windows/Types-of-glass

[5] Woolner, P. \& Hall, E. (2010). Noise in Schools: A Holistic Approach to the Issue. International Journal of Environmental Research and Public Health, vol. 7(8), pp. 3255-3269.

[6] Oral, G., Yener, A. and Bayazit, N., 2004. Building envelope design with the objective to ensure thermal, visual and acoustic comfort conditions. Building and Environment, 39(3), pp. 281-287.

[7] Double Glazing Info. (2008). Types of Glass [online]. [Accessed 28 February 2014]. Available at: http://www.double-glazing-info.com/ Choosing-your-windows/Types-of-glass

[8] Hien, W. and Istiadji, A., 2003. Effects of external shading devices on daylighting and natural ventilation. pp. 475-482.

[9] Carmody, J. and Haglund, K., 2006. External Shading Devices in Commercial Buildings. 